\title{
Historical iron tie-rods in vaulted structures: parametrical study through a scaled model
}

\author{
J. Mora-Gómez \\ DAStU, Dipartimento Architettura e Studi Urbani, \\ Politecnico di Milano, Italy
}

\begin{abstract}
Iron tie rods have been used for centuries both as auxiliary and as reinforcing elements for vaulted structures. Their presence in heritage buildings is widespread in some regions such as Italy, and in many cases they have become historical elements with their own value as testimony of past constructive solutions. The appreciation and study of these elements is an active field of research. Their conservation implies searching for a better understanding of the structural behaviour and the interactions between ties and masonry, which still is not fully understood. Through time, architectural manuals and treatises have evolved in their recommendations on the best way to apply them, mainly about the position and constructive solutions. This research is based on a case study that shows many different typologies due to consecutive reinforcing interventions. The structural performance of the different cases is studied through a simplified scaled model executed following Heyman's structural masonry theories and the correspondent limit analysis. Applying the reinforcements identified in the case study and treatises, the model has been subject to load tests, taking measurements of collapse load, impost displacement and formation of collapse mechanisms. Thus, it is studied directly in the model how every solution provides a different structural enhancement. Going further, the combination of tie-rods with other reinforcing methods has been analysed. Besides, the results are compared to a parallel limit analysis, in order to discuss some of the assumed simplifications taken in this type of analysis.

Keywords: tie-rods, masonry structures, vaulted structures, strengthening techniques, traditional constructive techniques.
\end{abstract}




\section{Introduction: historical iron tie-rods and the case of Santa Maria Lauretana in Tresivio (SO), Italy}

This work is part of the research developed within a $\mathrm{PhD}$ thesis in the Politecnico di Milano, on the topic of tie-rods used for arch and vault reinforcement and their consideration as historical elements. Used for centuries, their implementation is very often linked to important events in the buildings' history (restorations, earthquakes, additions...), leaving both a historical trace to be respected and a structural element to be integrated within future strengthening interventions.

Starting from a significant case-study, it has been possible to follow partly the development on the use of these elements, and the change on the recommendations about constructive solutions applied for them. This is linked not only to the evolution of constructive materials and details, but also to the development of theories and assumptions for the structural analysis of arched masonry elements. Due to this, one of the interesting observed features to change through time has been the recommendation on the theoretical optimum position of the tie-rods, along with their complementarity with other solutions.

There are several independent features that describe the action of tie-rods, and the possible combination with other reinforcing techniques makes the number of different solutions even higher. In this paper, it will be presented a parametrical study where all of these features, and their different values, are confronted directly, through an experimental campaign developed on a scaled mock-up.

\subsection{The case study: the sanctuary of Santa Maria Lauretana in Tresivio}

The basis of the design of the model used in the experimental campaign is a church located in Valtellina, in northern Italy. It was built in rather poor locally available materials and with reduced manpower, from mid- $17^{\text {th }}$ century to the first third of $19^{\text {th }}$ century. Even if the means were limited, the will was to erect an impressive building, with big dimensions and set on the top of a hill. Structural problems manifested almost from the completion. Consecutive strengthening interventions in time were limited to the implementation of tie-rods, in such an extensive way that nowadays their presence is a characteristic of the monument. Chronologically it is possible to spot four families [1]:

- Timber tie-rods in the immediate extrados, dated probably in 1798.

- Iron tie-rods at a position of approx. $30^{\circ}$ from the impost of the arch, from an extensive restoration made in 1874. This is subdivided according to two joint solutions, linked to the tensioning techniques and therefore to the pre-stress that it is possible to implement in them.

- Double steel tie-rods, implemented in the late 1960s as provisory solution.

- Finally, general and extensive strengthening works were performed by Eng. Prof. Lorenzo Jurina and Arch. Maspes, finished in 2000 and allowing the reopening after a 30 year closure. Along with reinforcement and stiffening of the foundations and confinement of the central dome, the intervention included the substitution of a tie-rod that failed suddenly. 


\section{Experimental campaign on mock-up}

\subsection{Model definition}

As a part of the research, it seemed interesting to include an experimental campaign in a scaled simplified model. Aware of the limitations of this methodology, and of the simplifications that it implies, the results are not to be interpreted directly to the real case-study or real structures, but are a mean of doing an internal and direct comparison of all the features defining the possibilities of reinforcement that could be implemented to a given arch.

The experimental campaign intended to cover a big range of parameters in order to confront them individually and to be able to obtain direct confrontation of different solutions applied to the same element. The opportunity arose from the availability of an experimental model, used in previous research for the analysis of the implementation of new reinforcing techniques like the Reinforced Arch (R.A.) [2-4]. This model consists of arches with several different geometries, composed by a high number of rigid timber voussoirs and with sanded paper attached to the interfaces. The approach was to obtain a model that follows Heyman's assumptions [5] for the analysis of masonry, this is, infinite and rigid compressive strength, absence of tensile strength, and impossibility of sliding among voussoirs. Besides, since the experimental campaign intends to confront a very high number of parameters, it was planned to perform a very high number of tests. Thus, it was necessary a model that didn't damage during the loading process or the collapse, and easy to operate and reassemble. This reasons led to the adaptation of the available model, including the abutments, designed according to the most common dimensioning rule found in the tradition [6] and to the proportion of the case-study. The dimensions of the model are expressed in Figure 1, and correspond to a scaling of the Santuario di Tresivio of $1: 12.5$, reflecting the proportions of span/abutment thickness and height, and the position of the tie-rods. Even if the real case is more similar to the segmental arch, the experimental campaign was carried out on all the arch geometries, and also with an artificial reduction of the abutment thickness in the base, in order to test cases with different value of thrust on the abutment.

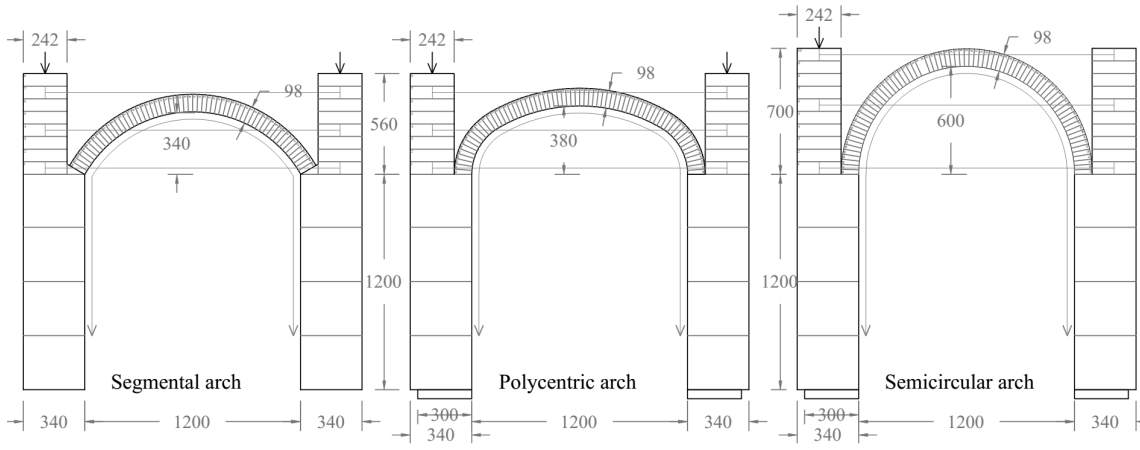

Figure 1: Description and geometry of the models. 
The used materials were beech timber for the arches, MDF for the abutments, and standard certified steel cable for the implementation of the tie-rods. The density was measured in the elements, and the mechanical properties considered for further analysis are expressed in Table 1. For the cables and MDF, the properties are taken from producer's documents. For the beech, the data is assumed from the indications in standards UNE-EN 1912 and UNE-EN 338 for a D40 strength-class, related to the measured density.

Table 1: $\quad$ Material properties.

\begin{tabular}{|l|c|c|c|c|}
\hline & Density & Elastic mod. & $\begin{array}{c}\text { Compressive } \\
\text { strength }\end{array}$ & $\begin{array}{c}\text { Tensile } \\
\text { strength }\end{array}$ \\
\hline Beech (arches) & $750 \mathrm{~kg} / \mathrm{m}^{3}$ & $1.8 \mathrm{e} 6 \mathrm{kN} / \mathrm{m}^{2}$ & $12600 \mathrm{kN} / \mathrm{m}^{2}$ & - \\
\hline $\begin{array}{l}\text { MDF panels } \\
\text { (abutments) }\end{array}$ & $720 \mathrm{~kg} / \mathrm{m}^{3}$ & $3.2 \mathrm{e} 5 \mathrm{kN} / \mathrm{m}^{2}$ & $16500 \mathrm{kN} / \mathrm{m}^{2}$ & - \\
\hline $\begin{array}{l}\text { Cables IX119 } 2 \mathrm{~mm} \\
\text { FASItaly }\end{array}$ & $0.02 \mathrm{~kg} / \mathrm{m}$ & $1.6 \mathrm{e} 8 \mathrm{kN} / \mathrm{m}^{2}$ & - & $3.5 \mathrm{kN}$ \\
\hline
\end{tabular}

The organization of the performed tests and the measured parameters are expressed in Table 2. The cases open in a tree-scheme, so that for every case of position of the tie-rod there are three possibilities of applied tension, and two positions of load application. The total number of tests has been 424 .

Table 2: $\quad$ Scheme of performed tests.

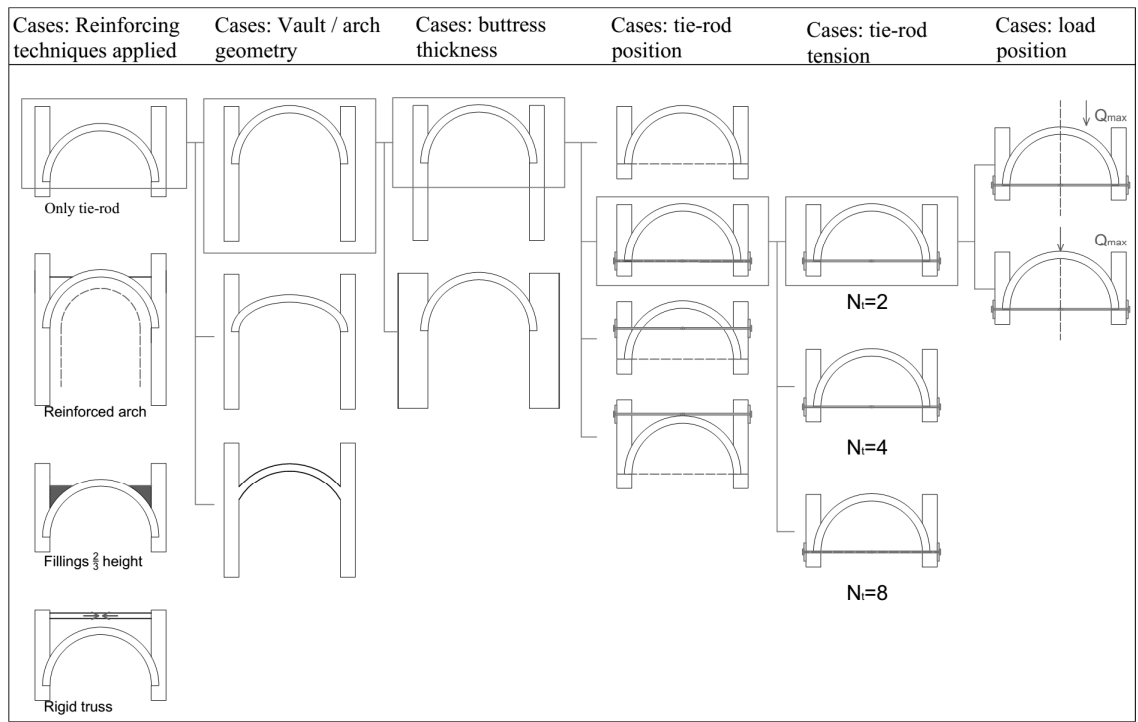

\subsection{Experimental procedure}

The procedure is based and adapted from previous works studying the effect of reinforcements in arched structures with scaled mock-ups [3, 4, 7, 8]. As 
aforesaid, it is very important to keep the same conditions for all the tests in order to make them confrontable, so special care and control has been taken in the whole process of assembling the abutments checking the geometry, centring and decentring the arch and the load application.

After a series of previous testing, and the consideration of several types of tests, the decision has been taken for simple incremental vertical loading tests, both in the central point of the arch (which leads to a 5-hinge mechanism collapse) and at approx. $1 / 4$ of the span (corresponding to a weak loading point for several geometries of the arch detected in [3], and leading to a 4-hinge mechanism). This decision is due to the will to maintain simplicity and ease allowing a big number of tests with small variations among them. Even if these loading tests do not correspond to realistic situations to be found in the casestudy, the incremental punctual loading seems a good methodology to assess how a given technique can improve the resistance of an arch in a basic and general way.

The loading process is done manually, by slow and constant addition of small weights in a container attached to the selected application point. The loading stops when the collapse hinges form and the mechanism develops. Each test is repeated twice to discard procedural errors and get mean values. The attained data are the collapse load, the displacement in the abutment, and photographic determination of the collapse mechanism. The general configuration and particular details are illustrated in Figures 2 and 3.

For the complementary reinforcing systems, further elements have been included, in order to reproduce the effect that they put in the structures. In particular, the included systems illustrated in Figure 4 have been:

- R.A., modelled trough an oiled sliding cable fixed to each voussoir with eyebolts, and with variable weights attached to simulate its resistance [3].

- Fillings, modelled with a fitted piece of high-density polystyrene, very rigid and providing reduced weight.

- Rigid truss, modelled with a timber rod fixed to the summit of the abutments.

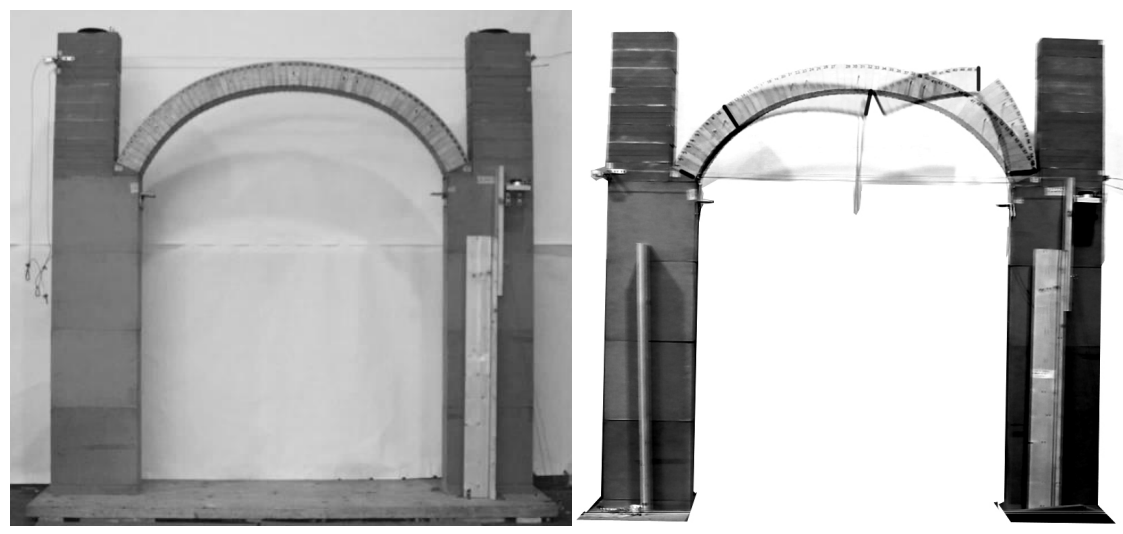

Figure 2: General view of the experiments and loading to collapse. 


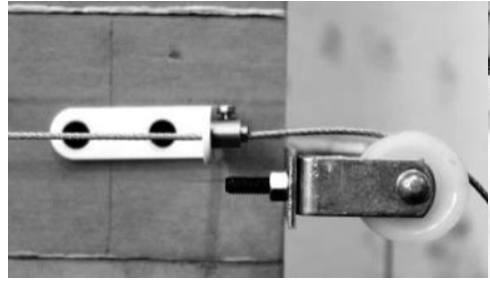

(a)

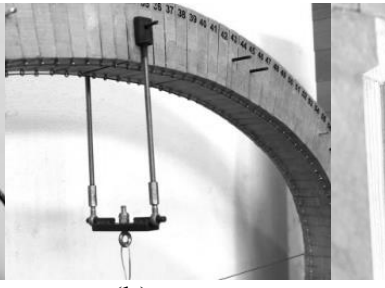

(b)

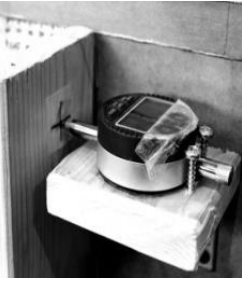

(c)

Figure 3: (a) Fixity of the cables for the simulation of the tie-rods; (b) Device for application of the load; (c) Measurement of the displacement of the abutment.

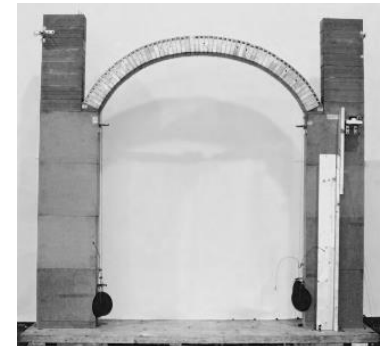

(a)

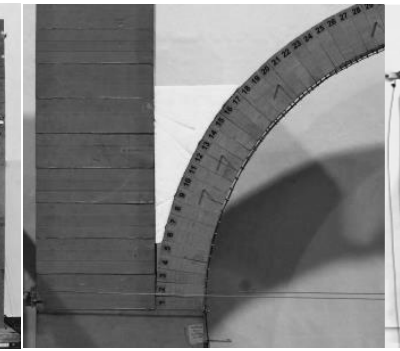

(b)

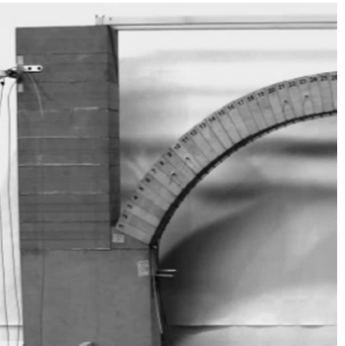

(c)

Figure 4: (a) Simulation of reinforced arch; (b) Simulation of fillings; (c) Simulation of rigid truss on summit.

\section{Results of the experimental campaign}

The experimental campaign has tried to cover a great variety, not only of reinforcing solutions, but also of their implementation to different arch geometries. Given that the attained data is repetitive due to the systematic testing plan, the result for only two geometries and for a central incremental load will be exposed in this paper. The chosen geometries are significant for giving an example of a high-thrust arch and a low-thrust arch. Additional comments about all the geometries will be discussed in the conclusions.

The data has been collected for every test as explained in the comparative of Figure 5 with selected cases of the segmental arch: collapse load, displacement of the abutment, and positions of the hinges in the collapse mechanism, as well as further remarks (for instance, variation of the hinges during the collapse process). It is interesting to see the changes in the formation of hinges and further collapse mechanism, confronting the results for different reinforcing techniques. In the examples given, the confrontation shows the capacities of the R.A. technique, especially if combined with tie-rods. 


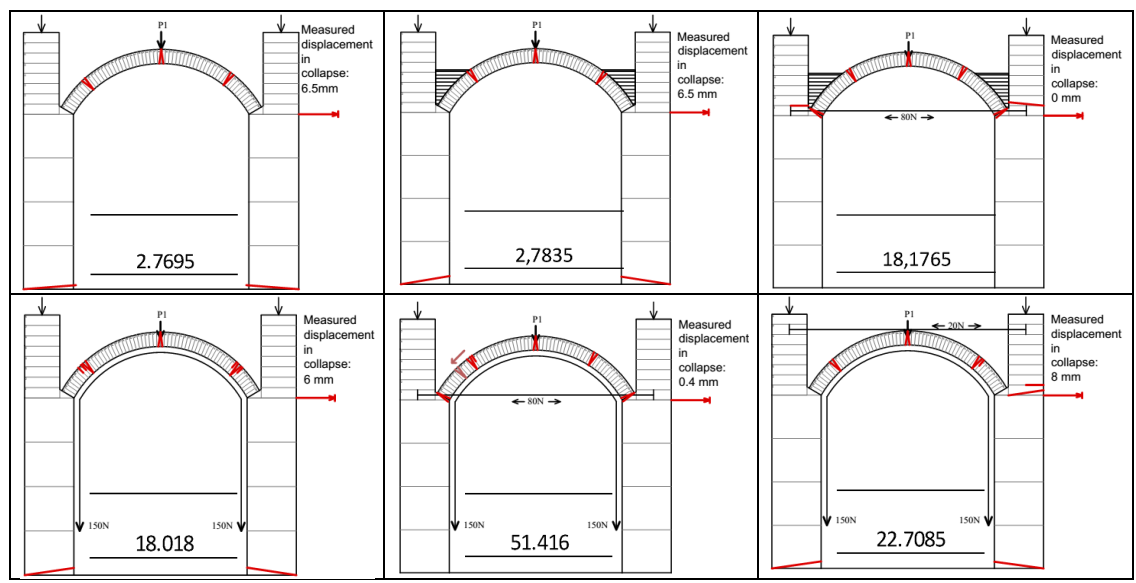

Figure 5: Example of retrieved data and analysed contrasts.

As for the confrontation of the collapse load, it is expressed in the example graphs provided in Figure 6. These have been elaborated forming groups according to the reinforcing technique that is applied complementarily to the tierods: Reinforced Arch, with applied tensions of $\mathrm{Nc}=40$ and $150 \mathrm{~N}$; Fillings and Truss. Each group is divided in three curves, each of them reflecting a position of the tie-rod, and how the collapse load increases with the applied pre-stress (starting from $\mathrm{Nt}=0$ meaning no tie-rod, and arriving to $80 \mathrm{~N}$ ).

For the arch with significant thrust potential (segmental), the first remark is how simply adding the tie-rod already doubles the initial collapse load. The increase of tension in the tie-rod increases this capacity, reaching values that are very near to the ones measured for tests with the arch standing on a fixed base instead of on abutments [3].

For the R.A., it is seen how the groups are similar, with the final attained load increasing in several magnitudes the one of the non-reinforced arch, as was discussed in [3]. In this experimental campaign, the interesting result is to discover how the combination of tie-rods and R.A. work. It is seen that only the Reinforced Arch is already able to increase the collapse load substantially. Nonetheless, the formed mechanisms concern the abutments. The implementation of the tie-rod more than doubles the collapse load, and further increase of its pre-stress takes its value even nearer to the ones measured on fixed imposts. Besides, it is seen how the most effective position is the impost, with decaying values as the tie-rod is moved up to the extrados.

For the combination with consistent fillings or diaphragms, the first remark is the absence of improvement if tie-rods are not applied. On the other hand, once applied, they prove to be a very effective combination, attaining loads that tenfold the initial one. Here, it is checked that the most effective position of the tie-rod is the one that lies closer to the fillings (and thus, in the case-study, in the position of $30^{\circ}$ measured from the springings), while the impost position lies in almost half these values, and the one in the extrados even lower. 
The experiences with the simulation of a rigid truss in the summit of the abutments have led to results that are practically the same (or in some cases even slightly worse) than the ones with only the tie-rod.
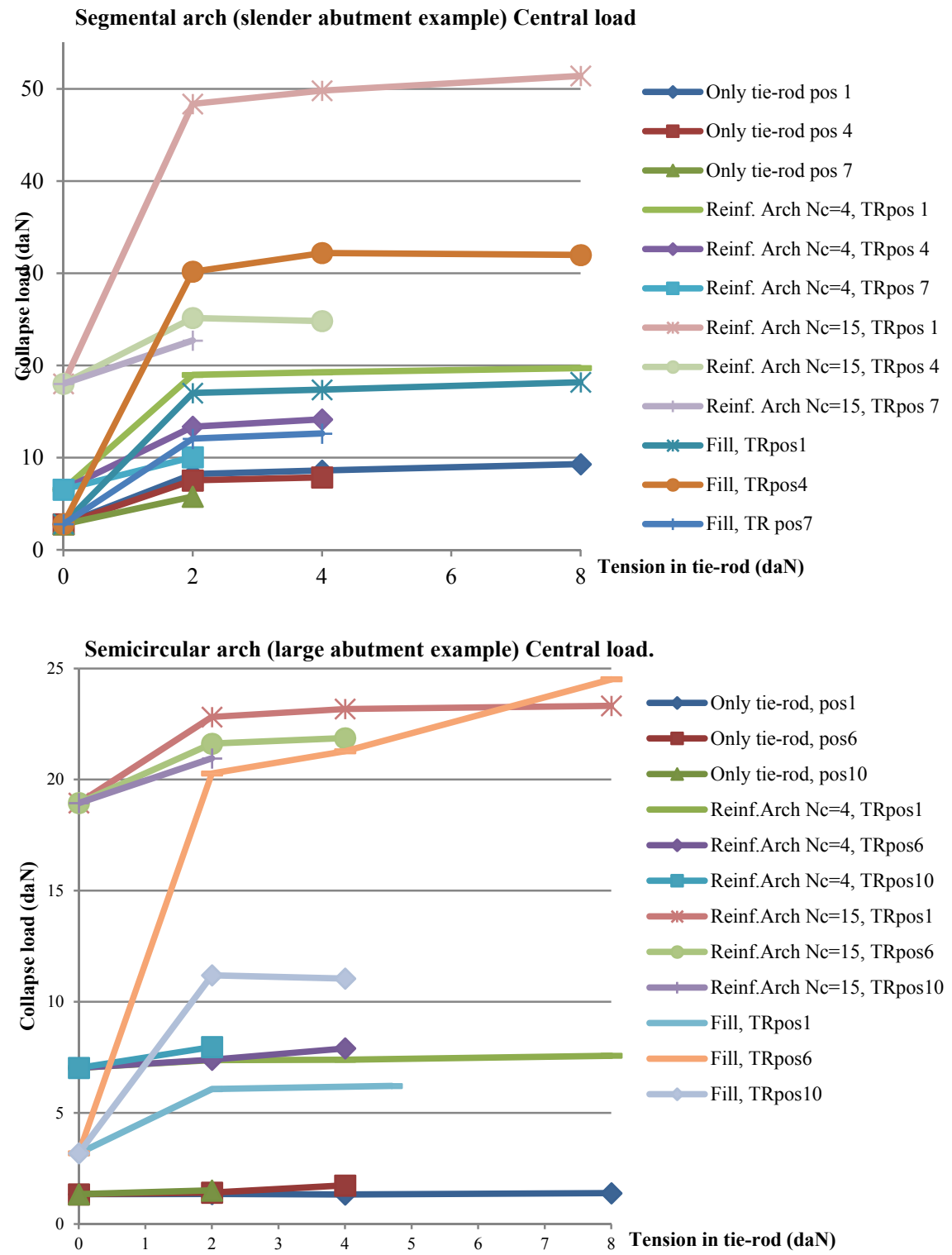

Figure 6: Collapse load for every case of reinforcement. 
The arch with a large abutment related to its thrust shows, for the simpler reinforcements, an expected behaviour: since the collapse mechanism forms in the arch without affecting the abutments, the implementation of the tie-rod is anecdotic, giving almost unnoticeable increases of collapse load. This is also applicable to the combination of tie-rod and truss.

Nonetheless it is still noticeable that tie-rods have the capability of collaborating with the R.A., especially when they are applied with a high pretension. This increase of loading capacity, though, is small.

The difference is very evident when the effect of fillings is added. Actually, its presence permits the thrust line to be redirected so that the abutments are involved in the collapse, and thus the presence of tie-rods is fundamental to make this reinforcement function properly.

\section{Confrontation with limit state analysis}

Parallel to the execution of the experimental campaign, the arches were analysed following the lower bound principle of limit analysis [5], as shown in Figure 7. The comparison with the real model has been interesting for some discrepancies. It is seen that the polycentric arch has a very small range of possibilities for thrust lines, although it is possible to find some within the geometry and should be stable. In the campaign, when this model was assembled without tie-rods, it collapsed in the de-centring process, and even with the help of the tie-rod, it showed to be very unstable. On the other hand, the segmental arch, with a very high range of possibilities of thrust lines, was very stable and its collapse modes always involved the abutment. For the semicircular arch, in the case of full abutment, as expected by the position of the thrust line, little difference was made by the implementation of the tie-rod.
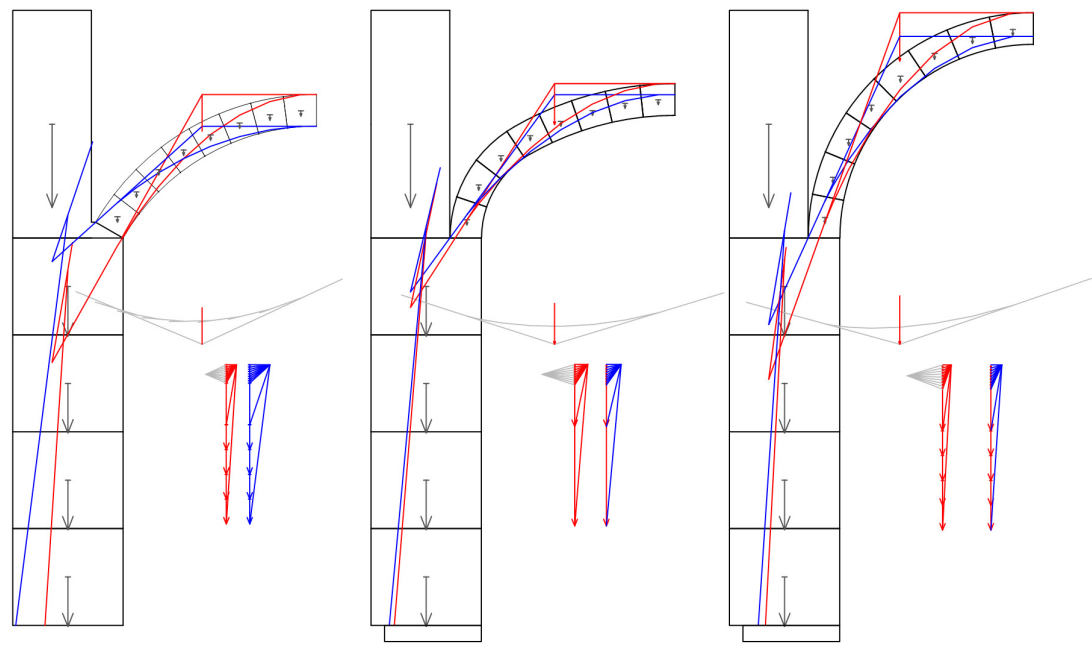

Figure 7: Graphic static analysis of the mock-up arches. 
Complementarily, they were modelled in RING code [9], developed by the University of Sheffield and using the principles of limit state analysis to trace the thrust line that it is possible to obtain for a given geometry, material and load. This way, it is also possible to obtain the load multiplier that would cause the collapse.

Despite its facility of use and intuitiveness, it does not allow to model the tierods, for which it is only possible to directly confront the arches without reinforcement on abutments, and the arches on fixed imposts as most direct approach to the ones using tie rods.

Table 3: Confrontation of RING and experimental results.

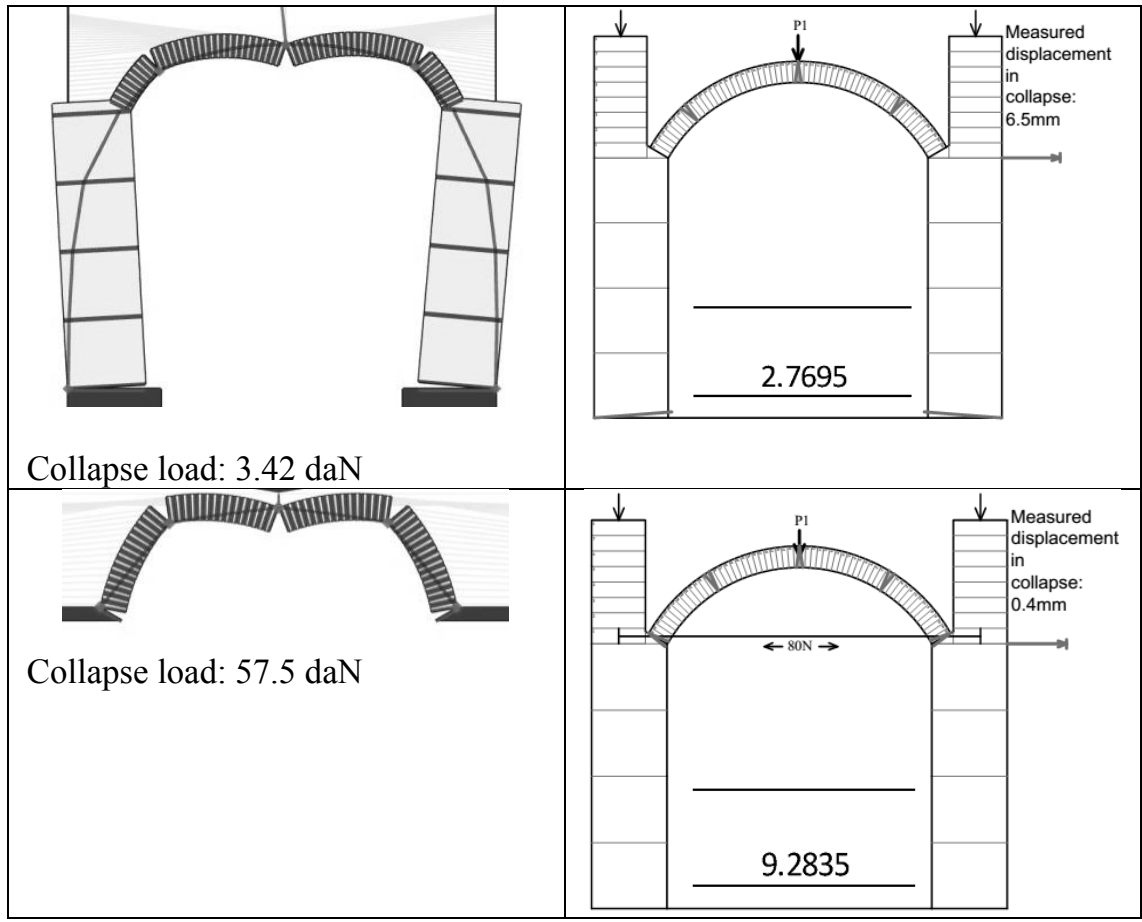

The example shown in Table 3 displays some of the discrepancies found when comparing the theoretical model with the experimental results. There are some remarkable observations:

- In general, higher values of collapse load in the theoretical model. This can be blamed on slight imperfections of the wood blocks, though for cases as the segmental arch on fixed imposts, theoretical results are overestimated (as it would be the case for the flat arch with infinite strength).

- The thrust in the experimental model is higher than in the theoretical one: in some cases in which the program predicted a failure only in the arch, in the experimental campaign the collapse mechanism included the abutments.

- In general, very good correspondence of the position of the hinges. 


\section{Conclusions and future work}

The simulation with this mock-up, though posing important simplifications of the real behaviour of masonry structures, seems a very helpful method for parametrical systematic studies as the one exposed in this paper. Besides, it is a very helpful tool for the assessment of methodologies that are difficult to simulate numerically. Aware of the limitations of this model (geometrical imperfections, higher elasticity, tie-rod with higher strength), the results are valid within the campaign, and not directly extrapolable to the case-study.

After studying in detail the differences of behaviour of a scaled arch modifying each of the parameters defining the structural assemble, the general remarks obtained are as follows:

- In those arches with enough abutment width (i.e., the collapse mechanism forms within the arch without affecting the abutments), the implementation of a tie-rod on its own does not increase the collapse load, as expected. Nonetheless, in the cases where it is combined with fillings or Reinforced Arch, tie-rods provide an improvement even in this case.

- In general, and when the arch is not reinforced by any other technique, the position of the tie-rod that offers a better increase of the load capacity is fixing the imposts, for all the geometries.

- Good approximation to limit analysis, as long as Heyman's principles are respected. The tests in which high compression of the timber is attained might not be relevant when trying to extrapolate results to masonry structures. On the other hand, and as observed in [8], also in this case the collapse load of the scaled model is lower than what expected according to limit analysis. This could be blamed on slight imperfections in the high number of contacts.

- Great compatibility and complementarity of the tie-rods with the Reinforced Arch method [2]. Even if only this technique can already improve greatly the performance of the arch, the full potential is shown when combined with tierods, fixing the imposts.

- Rigid trusses (for example, substitution of old timber trusses with reinforced concrete ones) don't offer any substantial asset combined with tie-rods, other than the possibility of increasing their pre-stress.

- For the observed case-study, the ancient rule of positioning the tie-rod at $30^{\circ}$ from the springing seems to be very effective because of the combination with fillings (as long as they have the capacity of transmitting stresses).

- In general, the increase of pre-tension in the tie-rod does not lead to significant increase of the collapse load, as was also stated in $[7,8]$.

Future work includes the possibility of analysing the change in the dynamic behaviour of a masonry arch due to the implementation of a tie-rod, in its different variations. This possibility was excluded from this experimental campaign as the slenderness of the model didn't allow attaining satisfactory results in the preliminary testing during the design of the campaign.

Further detailed FEM modelling of the case study will allow having a further confrontation with the attained results, and discussing the simplifications that were assumed in this experimental model. 


\section{Acknowledgements}

To Arch. Maurizio Giglio for his indispensable help and advice on the technical details and procedures to develop the campaign systematically. To the laboratory and staff from Laboratorio di Prove Materiali in Politecnico di Milano, for their constant help and availability. To FAS Italy S.L., for providing the necessary material.

\section{References}

[1] L. Jurina and J. Mora-Gómez, "Tie-rods within vaulted masonry structures as a sign of history: the case of Santa Casa Lauretana in Tresivio.," in REUSO $2{ }^{\circ}$ convegno internazionale sulla documentazione, conservazione $e$ recupero del patrimonio architettonico e sulla tutela paesaggistica., Florence, November 2014.

[2] "Lorenzo Jurina," [Online]. Available: www.jurina.it.

[3] M. Giglio and L. Jurina, Consolidamento di archi e volte in muratura mediante la tecnica dell'arco armato. Approccio sperimentale., Milan: Politecnico di Milano. Master Thesis, 2008.

[4] S. Bonfigliuoli and L. Jurina, Consolidamento strutturale e antisismico di archi e volte in muratura: una sperimentazione sulla tecnica dell'arco armato., Milan: Politecnico di Milano. Master Thesis, 2011.

[5] J. Heyman, The stone skeleton: structural engineering of masonry architecture., Cambridge: Cambridge University Press, 1995.

[6] S. Huerta, Arcos, bóvedas y cúpulas : geometria y equilibrio en el cálculo tradicional de estructuras de fábrica., Madrid: Instituto Juan De Herrera, 2004.

[7] C. Calderini, S. Lagomarsino, M. Rossi, G. Decanio, M. Mongelli and I. Roselli, "Seismic Behaviour of masonry arches with tie-rods: Dynamic tests on a scale model.," in 15th WCEE World conference on earthquake engineering, Lisbon, 2012.

[8] C. Calderini and S. Lagomarsino, "Seismic response of masonry arches reinforced by tie-rods: static tests on a scale model," Journal of structural engineering, Vols. 10.1061/(ASCE)ST.1943-541X.0001079, 2014.

[9] "Limit State Ring: Masonry arch analysis software," [Online]. Available: http://www.limitstate.com/ring 